\title{
Niobium enhanced europium ion luminescence in hafnia nanocrystals
}

\author{
K. Laganovska*, I. Bite, A. Zolotarjovs, K. Smits \\ Institute of Solid State Physics, University of Latvia, Latvia
}

A R T I C L E I N F O

\section{Keywords:}

Hafnia

Luminescence

Eu3+

Charge compensation

Judd Ofelt

\begin{abstract}
A B S T R A C T
In this work we demonstrate a method where by adding $\mathrm{Nb}$ ions, $\mathrm{Ln}^{3+}$ ion luminescence intensity in $\mathrm{HfO}_{2}$ is increased for up to 15 times (in a sample containing $5 \mathrm{~mol} \% \mathrm{Eu}$ ). The effect is described as niobium acting as a charge compensator and neutralizing the charge resulting from $\mathrm{Ln}^{3+}$ ion insertion in $\mathrm{Hf}^{4+}$ site and hence reducing the number of defects present. This is the second system where such an effect was observed, so it is expected that other metal oxides would show the same effect. The optical properties of $\mathrm{HfO}_{2}$ : $\mathrm{Eu}^{3+}$ and $\mathrm{HfO}_{2}$ : $\mathrm{Eu}^{3+}, \mathrm{Nb}^{5+}$, synthesized using the sol-gel method and annealed at various temperatures are studied. A conclusion that the structure of hafnia does not affect luminescence intensity directly and a larger role is played by factors such as defect presence and the size of the particles is drawn based on XRD and TSL measurements. Timeresolved luminescence measurements were also carried out and significant changes depending on dopant concentration and annealing temperatures were observed. Judd Ofelt theory was used to determine quantum efficiency and the local symmetry of $\mathrm{Eu}^{3+}$ ion sites.
\end{abstract}

\section{Introduction}

Many modern applications like LED emitters and various scintillators require durable luminescent materials. These applications are often based on wide band gap materials doped with rare earth elements such as $\mathrm{HfO}_{2}$ or $\mathrm{ZrO}_{2}$ [1-3]. The wide band gap also ensures that the thermal quenching effects of luminescence are lower thus increasing the overall luminescence intensity [4,5]. Besides promising optical properties hafnia is also a high-k material and has already been applied in various microelectronic devices [6,7]. It is one of the most promising materials in the search for a replacement of $\mathrm{SiO}_{2}$ [4], for which a reduction in size any further is difficult to achieve due to its relatively low dielectric permittivity constant.

Both optical and electric properties in hafnia depend on crystal phase and defects. Undoped hafnia is expected to exist in monoclinic phase at room temperature and ambient pressure [2]; however, by adding dopants with lower valence or by decreasing the size of nanocrystals (crystal sizes below $30 \mathrm{~nm}$ ) and thus increasing the surface energy, the tetragonal phases can be stabilized [8]. Theoretical calculations demonstrate that the tetragonal or cubic phases can be stabilized by oxygen vacancies alone [9]. This effect was proven by experimental studies performed on $\mathrm{ZrO}_{2}$ matrix [10]. Recent studies [7,11,12] showed that in zirconia a strong overall reduction in $\mathrm{Ln}^{3+}$ luminescence intensity can be explained by intrinsic defects. However, the implementation of $\mathrm{Nb}^{5+}$ ions as charge compensators in the matrix can change the defect concentration and distribution thus highly increasing the resulting intensity. Zirconia and hafnia have very similar optical, electrical and structural properties, therefore, they are called twin oxides. Hence in this study, we are looking at $\mathrm{Nb}$ effect on Eu ion luminescence in hafnia.

\section{Materials and methods}

\subsection{Materials}

Hafnium tetrachloride $\left(\mathrm{HfCl}_{4}\right.$, purity $\left.98 \%\right)$, europium oxide $\left(\mathrm{Eu}_{2} \mathrm{O}_{3}\right.$, purity $99,99 \%$ ), niobium pentachloride $\left(\mathrm{NbCl}_{5}\right.$, purity $99 \%$ ), were used as the starting materials and were purchased from Alfa Aesar. Citric acid $\left(\mathrm{C}_{6} \mathrm{H}_{8} \mathrm{O}_{7}\right.$, purity $\left.99,5 \%\right)$ and ethylene glycol $\left(\mathrm{HO}\left(\mathrm{CH}_{2}\right)_{2} \mathrm{OH}\right.$, purity 99\%) were used as a complexing and chelating agents, both purchased from Sigma Aldrich. Nitric acid $\left(\mathrm{HNO}_{3}\right.$, assay $\left.65 \%\right)$ was used to dissolve $\mathrm{Eu}_{2} \mathrm{O}_{3}$ and was purchased from Sigma Aldrich. Methanol $\left(\mathrm{CH}_{3} \mathrm{OH}\right.$, purity $99,9 \%$ ) was used to dissolve $\mathrm{NbCl} 5$ and was purchased from AppliChem. Analytical grade chemicals were used without any further purification.

\subsection{Synthesis of doped $\mathrm{HfO}_{2}$ nanoparticles}

In the present work, $\mathrm{HfO}_{2}: \mathrm{Eu}^{3+}$ and $\mathrm{HfO}_{2}: \mathrm{Eu}^{3+}, \mathrm{Nb}^{5+}$ nanoparticles were synthesized using a sol-gel polymerized complex method following the procedure described by Ramos-González et al. [13]. The molar ratio of metal ions, citric acid and ethylene glycol was 1:1:4,

\footnotetext{
* Corresponding author.

E-mail address: katrina.laganovska@cfi.lu.lv (K. Laganovska).
} 
respectively. Three different doped $\mathrm{HfO}_{2}$ samples were synthesized, where molar concentrations of $\mathrm{Eu}^{3+}$ ions were 5 and $10 \mathrm{~mol} \%$, and the molar concentration of $\mathrm{Nb}^{5+}$ ions was $5 \mathrm{~mol} \%$. To avoid the formation of niobium oxide, the appropriate amount of $\mathrm{NbCl}_{5}$ was dissolved in methanol and was added dropwise to the metal citrate complex solution while constantly stirred. When gel consistency was obtained, this gel was heated at $350{ }^{\circ} \mathrm{C}$ in an open oven for $2 \mathrm{~h}$ for nitric oxide elimination and a black powder was obtained. After synthesis, each sample was split into three parts and calcined at $800{ }^{\circ} \mathrm{C}, 1000^{\circ} \mathrm{C}$ and $1200{ }^{\circ} \mathrm{C}$ for $2 \mathrm{~h}$ and as a result, white powders were obtained.

\subsection{Measurement methods}

The crystalline structure of the samples was determined by X-ray diffraction (XRD) using an X-ray diffractometer (X'Pert Pro MPD) with $\mathrm{Cu}-\mathrm{K} \alpha$ radiation $(\lambda=1.54 \mathrm{~nm})$. Crystalline sizes were not measured but are roughly estimated based on previous research.

Luminescence measurements were performed using two different excitation sources: a YAG laser FQSS266 (CryLas GmbH) 4th harmonic at $266 \mathrm{~nm}(4.66 \mathrm{eV})$ for photoluminescence measurements at room temperature and an X-ray tube with a tungsten anode operated at $30 \mathrm{kV}$ and $10 \mathrm{~mA}$ for TSL measurements.

All samples were pressed into tablets of equal size, which allowed for intensity comparison between the samples. The luminescence spectra were recorded using an Andor Shamrock B-303i spectrograph equipped with a CCD camera (Andor DU-401A-BV).

The decay kinetics of luminescence were measured using a photon counting head H8259-02 (HAMAMATSU) and a P7887 counting board (Fast ComTec $\mathrm{GmbH}$ ) with minimal time bin $0.25 \mathrm{~ns}$. The time resolution of the system was $1 \mathrm{~ns}$.

\section{Results and discussion}

Earlier works show that maximum luminescence intensity is acquired at $5 \mathrm{~mol} \%$ Eu concentration [14-16], therefore a sample of $5 \mathrm{~mol}$ $\%$ Eu was chosen as a reference. However, the $5 \%$ of Eu is not enough to fully stabilize the tetragonal phase at higher annealing temperatures (with larger grain sizes of over $30 \mathrm{~nm}$ ). To assist the phase stabilization at higher temperatures, an additional sample with a higher concentration of $10 \mathrm{~mol} \% \mathrm{Eu}$ was chosen. The aim of this research was to study the role of $\mathrm{Nb}$ ions in the crystalline structure, and $\mathrm{Nb}^{5+}$ ion concentration was chosen to match the lanthanide concentration, similar to previous studies $[10,17]$. This decision was based on the fact that for each pair of ions only one oxygen vacancy is needed to compensate the charge. No vacancies are needed to form monoclinic phase, which means that $\mathrm{Ln}^{3+}$ ions are non-uniformly distributed in the matrix and tend to agglomerate (especially at higher temperatures monoclinic phase and large grain size). Samples with less than $5 \%$ content did not seem to provide any additional information and were not studied. A lower luminescence intensity and monoclinic phase would be expected as is seen in similar studies in $\mathrm{Zr}[15,14]$.

As it is expected for the structure and the resulting luminescence intensity of hafnia to be dependent on the size of nanocrystal grains, all samples were annealed at three different temperatures: $800{ }^{\circ} \mathrm{C}, 1000^{\circ} \mathrm{C}$, $1200^{\circ} \mathrm{C}$, similar to the approach used in other research works $[11,10,14]$.

X-ray diffraction (XRD) data (Fig. 1) reveals that when the annealing temperature was increased to $1200{ }^{\circ} \mathrm{C}$, phase transformation from tetragonal to monoclinic started taking place in the sample 5Eu ( $5 \mathrm{~mol} \% \mathrm{Eu}$ ). This phase transformation is assumed to happen due to nanocrystal grain size increase which results in excess surface energy being insufficient for stabilization [10]. For the sample containing $\mathrm{Nb}$, the monoclinic phase was dominant for all annealing temperatures and at lower temperatures, besides the presence of monoclinic and tetragonal phases, additional phases of $\mathrm{Nb}_{2} \mathrm{O}_{5}$ can be seen. This means that the chosen method of synthesis does not ensure the creation of pure

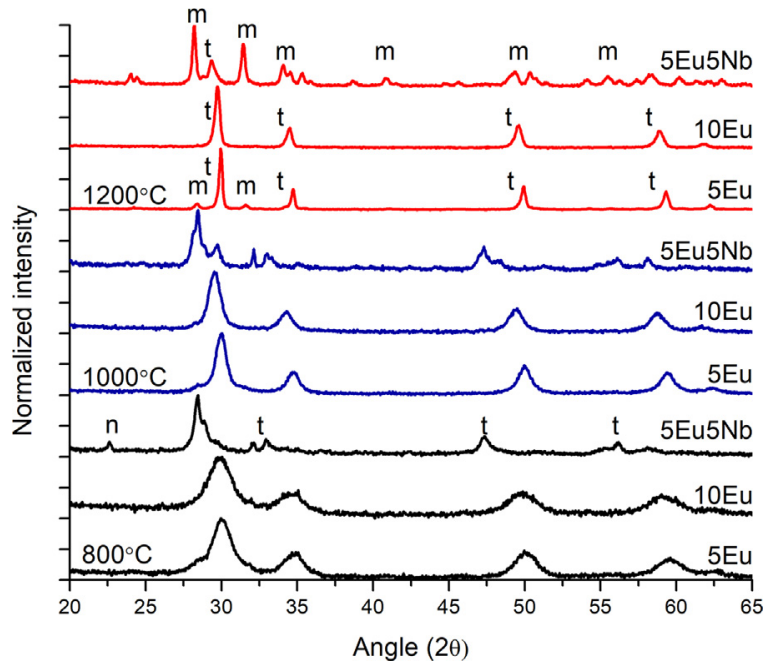

Fig. 1. Hafnia structure dependence for all annealing temperatures and dopant concentrations (XRD).

hafnia phases only, although niobium related phases disappear with the increase of the annealing temperature. Previous research demonstrates that inability to remain stable in a tetragonal phase for samples containing $\mathrm{Nb}$ is due to the resulting oxygen vacancy decrease in the crystallites [11]. $\mathrm{Ln}^{3+}$ ions are expected to not take part in tetragonal phase stabilizations due to oxygen vacancies not forming as a result of the charge compensation. Due to the oxygen vacancy reduction when doping with $\mathrm{Nb}$ ions, the lattice constant increases and according to Braggs law, the tetragonal peaks shift to lower angles as compared to samples doped only with $\mathrm{Eu}^{3+}$. Crystallite sizes were calculated using the Scherrer equation [18] and were found to be (in $\mathrm{nm}$ ): $5.8,10.6$, 48.4 for $5 \mathrm{Eu}$ samples, 5.3, 9.4, 26.5 for $10 \mathrm{Eu}$ and 13.4, 16.4, 45.5 for 5 Eu5Nb for annealing temperatures of $800{ }^{\circ} \mathrm{C}, 1000^{\circ} \mathrm{C}, 1200{ }^{\circ} \mathrm{C}$, respectively.

Sample 10Eu (10 mol\% Eu) maintained a steady tetragonal phase for all annealing temperatures due to the relatively large $\mathrm{Ln}^{3+}$ concentration. It can be seen that the stabilization of tetragonal phases is dependent on $\mathrm{Eu}$ ion concentration and $5 \mathrm{~mol} \%$ is not sufficient for higher $\left(>1000^{\circ} \mathrm{C}\right)$ annealing temperatures. However the concentration of $5 \mathrm{~mol} \%$ in various metal oxides is considered to be optimal for maximum luminescence intensity and phase stabilization $[11,14]$.

The oxygen vacancies in the $\mathrm{HfO}_{2}$ matrix act as electron traps and as such, they have their characteristic TSL (Fig. 2) curves. Therefore, to determine the relative number of defects in samples with and without $\mathrm{Nb}$, thermostimulated luminescence measurements were performed for



Fig. 2. TSL intensity distribution for peaks at $613 \mathrm{~nm}$. 


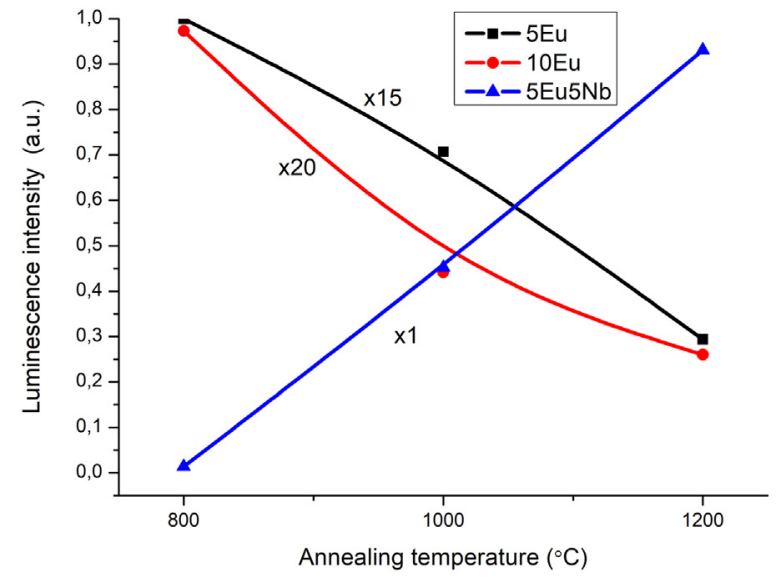

Fig. 3. Integrated photoluminescence intensity (570-670 $\mathrm{nm}$ range) dependence on annealing temperatures.

samples $5 \mathrm{Eu}$ and $5 \mathrm{Eu} 5 \mathrm{Nb}(5 \mathrm{~mol} \% \mathrm{Eu}$ and $5 \mathrm{~mol} \% \mathrm{Nb})$, annealed at $1200^{\circ} \mathrm{C}$. The spectra show $\mathrm{Eu}$ ion luminescence. TSL peaks for the ${ }^{5} \mathrm{D}_{0} \rightarrow{ }^{7} \mathrm{~F}_{2}$ transition were monitored over all temperatures. With a geometric factor $\mu_{g}=0.46$, the peak at $220 \mathrm{~K}$ is somewhere in between the first- and second-order kinetics [19]. Possibly meaning that the probability of retrapping is not absolutely negligible (as it would be for first-order kinetics), but it also does not reach a full second-order kinetic status. Luminescence intensity throughout heating was ten times greater for the sample 5Eu, confirming a significant decrease in defects (electron traps) for the sample containing $\mathrm{Nb}$, of which most are assumed to be oxygen vacancies [20].

For samples annealed at $800{ }^{\circ} \mathrm{C}$, the most intense luminescence was observed for the sample containing 5\% Eu (Fig. 3) This observation correlates with previous results obtained for Eu doped hafnia $[14,16]$ and zirconia [21] where the optimal concentration for maximum Eu luminescence was also found to be $5 \%$. The lower luminescence intensity of the sample containing $10 \mathrm{~mol} \% \mathrm{Eu}$ can be explained by concentration quenching $[14,15]$. With the increase of annealing temperatures, oxygen vacancies are thought to relocate between $\mathrm{Ln}^{3+}$ ions wherever charge compensation is needed. The distance to the oxygen vacancies becomes smaller as the temperature rises, thus increasing the chances for the energy coming from $\mathrm{Ln}^{3+}$ ions to get trapped in the defects.

Luminescence intensity for the $\mathrm{Nb}$ doped sample increases by a great margin for samples annealed at higher temperatures. We associate the lesser luminescence intensity seen at lower annealing temperatures with $\mathrm{Eu}$ ion mixing with $\mathrm{Nb}_{2} \mathrm{O}_{5}$ phases, as the tenfold increase in luminescence for higher temperatures could not be explained solely by larger particle sizes or a decrease in defects.

At $1000{ }^{\circ} \mathrm{C}$ and $1200{ }^{\circ} \mathrm{C}$ the most intense luminescence was observed for the sample containing $\mathrm{Nb}$, excluding the possibility that the increase in intensity of the $\mathrm{Nb}$ doped samples is a positive effect of $\mathrm{Nb}_{2} \mathrm{O}_{5}$ presence. Despite the larger grain sizes, with the increase in annealing temperature from $800^{\circ} \mathrm{C}$ to $1200^{\circ} \mathrm{C}$ the luminescence intensity halves for samples without $\mathrm{Nb}$. This counterintuitive behaviour can be explained with the cation inability to diffuse at temperatures below $1200^{\circ} \mathrm{C}$, therefore an anion diffusion takes place in the oxygen sublattice. The luminescence quenching is explained with oxygen vacancies present in the near vicinity of Eu ion (in the first coordination sphere). Similar behaviour has been shown in other research works [22].

The peak at $607 \mathrm{~nm}$ related to ${ }^{5} \mathrm{D}_{0} \rightarrow{ }^{7} \mathrm{~F}_{2}$ transition in Eu ions is related to oxygen vacancy presence in Eu surroundings [23]. Fig. 4 shows the spectral distribution at all annealing temperatures for the sample 5Eu. A new line at $607 \mathrm{~nm}$ appears when the annealing temperature changes from $800{ }^{\circ} \mathrm{C}$ to $1000{ }^{\circ} \mathrm{C}$, which fits the description

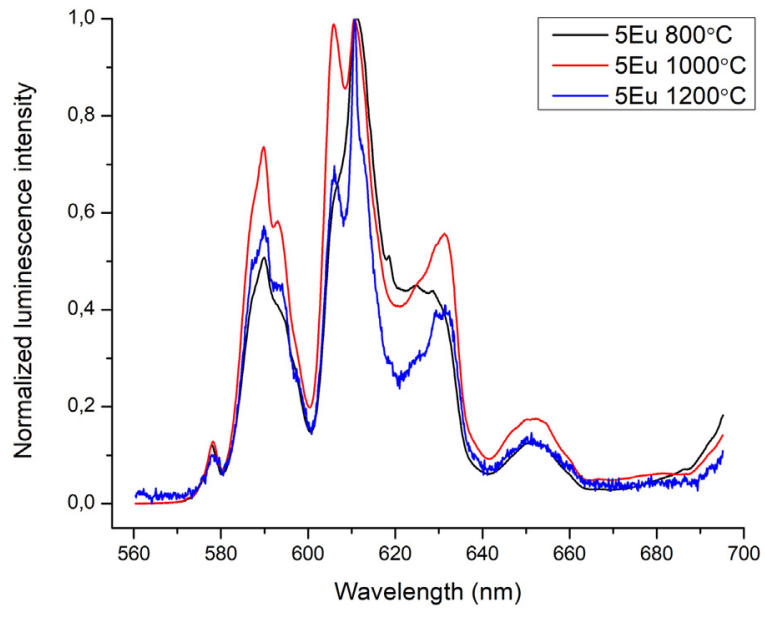

Fig. 4. Spectral distribution for the sample containing $5 \mathrm{~mol} \% \mathrm{Eu}$.

presented in [23], however, the intensity decreases again at higher temperatures. From XRD measurements it can be seen that for the sample $5 \mathrm{Eu}$, a phase shift starts taking place from tetragonal to monoclinic. For the stabilization of the tetragonal phase, oxygen vacancies are needed, however they are not necessary for the monoclinic phase. At $1100-1300{ }^{\circ} \mathrm{C}$ cation diffusion starts so the luminescence quenching can be explained by Eu ion agglomeration.

Due to the tetragonal phase being associated with the most efficient luminescence in previous studies of zirconia [23-25] it might seem that luminescence intensity would increase significantly if a tetragonal or cubic phase was achieved for hafnia doped with $\mathrm{Nb}$ too. However recent studies have shown that an increase in luminescence intensity occurs even after phase change from tetragonal to monoclinic in $\mathrm{Er}, \mathrm{Nb}$ or $\mathrm{Eu}, \mathrm{Nb}$ doped $\mathrm{ZrO}_{2}[12,10]$, which leads to think that both luminescence intensity and spectral distribution is mostly influenced by structure related defects (such as oxygen vacancies) and less so by local crystal field differences between monoclinic and tetragonal structures [26].

The spectral distribution in Fig. 5 shows that the peak at $607 \mathrm{~nm}$ for the sample containing $\mathrm{Nb}$ is greatly reduced in intensity as compared to the other samples. The changes in the crystalline environment change the distribution of oxygen vacancies present in the lattice and is the main contributor to changes in luminescence spectrum.

As magnetic dipole transitions ${ }^{5} \mathrm{D}_{0} \rightarrow{ }^{7} \mathrm{~F}_{1}$ are assumed to be unaffected by local crystal fields (as opposed to electric dipole transition ${ }^{5} \mathrm{D}_{0} \rightarrow{ }^{7} \mathrm{~F}_{2}$ ) [27,28], a local symmetry evaluation using the relation between the electric dipole and magnetic dipole intensities is presented.

Fig. 6 shows that the overall symmetry for samples containing $\mathrm{Nb}$ is

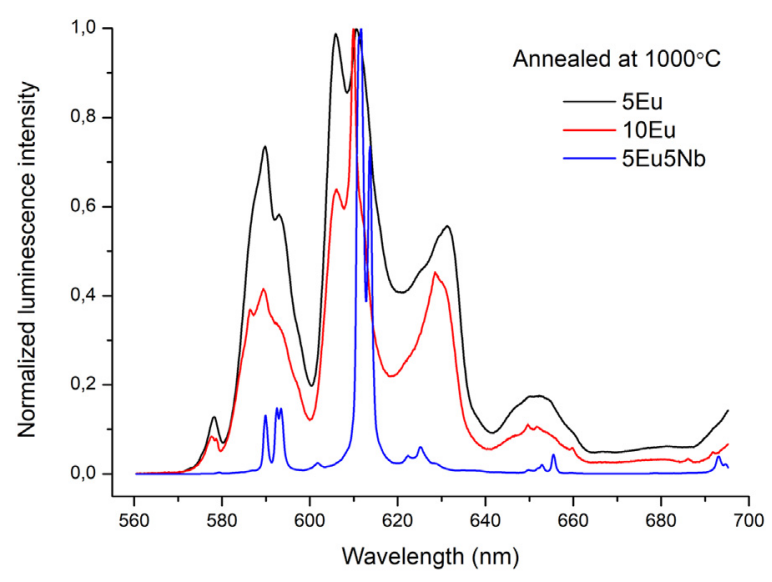

Fig. 5. Spectral distribution for all samples annealed at $1000^{\circ} \mathrm{C}$. 


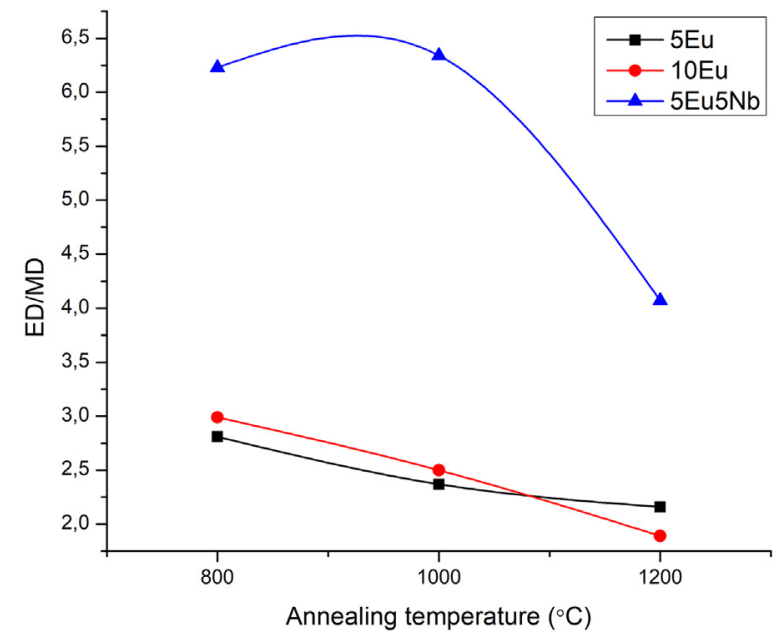

Fig. 6. Local symmetry determined by the electric/magnetic dipole relation.

significantly lower, though, increases as the grain size becomes larger (at $1200{ }^{\circ} \mathrm{C}$ ). Symmetry for samples without $\mathrm{Nb}$ is higher and more allied. The observed results again lead to think that luminescence intensity is more related to intrinsic defects rather than the local crystal field influence.

Luminescence decay is strongly dependent on the presence of defects present in hafnia. Time-resolved luminescence measurements were made (Fig. 7) and by integrating the area of the obtained kinetics, the slow to fast component ratio was determined (Table 1). Luminescence decays showed complex nature and therefore the approximation was divided in three parts. All ratios correlate with luminescence intensity well - the smaller the ratio of slow to fast, the greater the luminescence intensity, with the exception of the $613 \mathrm{~nm}$ line for samples containing $\mathrm{Nb}$, for which a different fast component mechanism seems to be in place. Combined with luminescence intensity results, this ratio generally indicates that the transition is not only more probable, but also energy transfer is taking place and nonradiative transitions have become more dominant Table 2 .

\subsection{Judd-Ofelt analysis}

For the calculations of spontaneous emission probability and the quantum efficiency Judd-Ofelt theory was applied to the emission spectra and the necessary parameters were calculated as is described in this paragraph. Due to the fact that for Eu ${ }^{3+}$ electric dipole ${ }^{5} \mathrm{D}_{0} \rightarrow{ }^{7} \mathrm{~F}_{2,4,6}$ transitions depend only on one squared reduced matrix element [29], the experimental $\Omega_{\lambda}$ intensities can be calculated from the ratio of the single MD transition ${ }^{5} \mathrm{D}_{0} \rightarrow{ }^{7} \mathrm{~F}_{1}$ to ED transitions and are determined by the following formula [30]:

$\Omega_{\lambda}=\frac{D_{m d} \nu_{1}^{3}}{e^{2} v_{\lambda}^{3}} \frac{9 n^{3}}{n\left(n^{2}+2\right)^{2}\left|\left\langle\Psi J\left\|U^{(\lambda)}\right\| \Psi^{\prime} J^{\prime}\right\rangle\right|^{2}} \frac{\int I_{\lambda}(\nu) d \nu}{\int I_{1}(\nu) d \nu}$

where $\mathrm{D}_{m d}$ is assumed to be $9.6 \times 10^{-42} \mathrm{esu}^{2} \mathrm{~cm}^{2}$ according to previous calculations [31]. e is the elementary charge $4.803 \times 10^{-10} \mathrm{esu}, \mathrm{n}$ is the refractive index $2.08[32]$ and $\left|\left\langle\Psi J\left\|U^{(\lambda)}\right\| \Psi^{\prime} J^{\prime}\right\rangle\right|^{2}$ are the squared reduced matrix elements for $\mathrm{Eu}^{3+}$ that are independent of the host
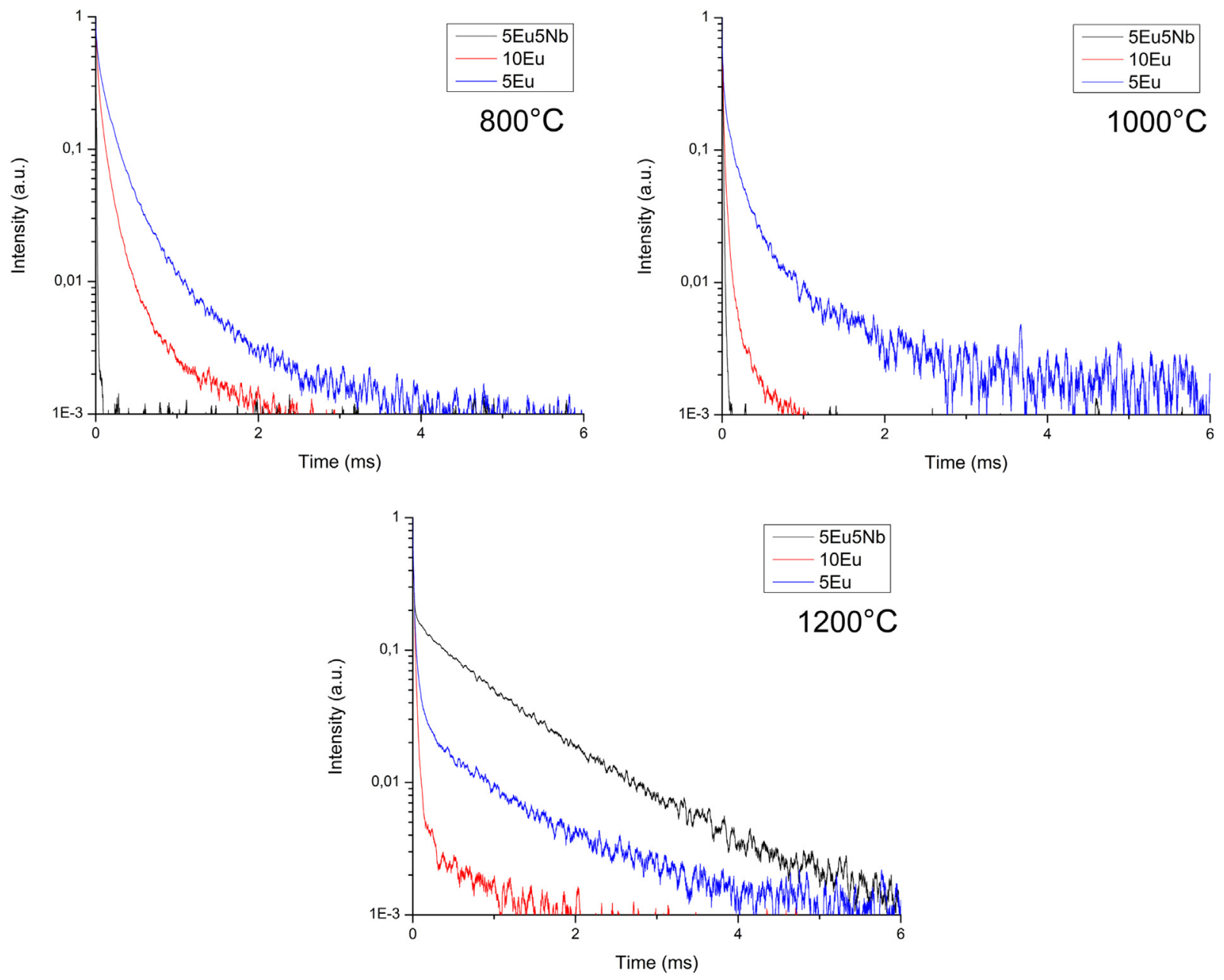

Fig. 7. Time resolved luminescence measurements for samples annealed at $800^{\circ} \mathrm{C}$ (upper left), $1000^{\circ} \mathrm{C}$ (upper right) and $1200^{\circ} \mathrm{C}$ (bottom). 
Table 1

Integrated area ratio of the slow component $(30 \mu \mathrm{s}$ to $5 \mathrm{~ms})$ versus the fast component $(0-30 \mu \mathrm{s})$.

\begin{tabular}{|c|c|c|c|c|c|c|c|c|c|}
\hline \multirow[b]{2}{*}{$\mathrm{nm}$} & \multicolumn{3}{|l|}{$5 E u$} & \multicolumn{3}{|l|}{$10 \mathrm{Eu}$} & \multicolumn{3}{|l|}{$5 E u 5 N b$} \\
\hline & $800^{\circ} \mathrm{C}$ & $1000^{\circ} \mathrm{C}$ & $1200{ }^{\circ} \mathrm{C}$ & $800{ }^{\circ} \mathrm{C}$ & $1000^{\circ} \mathrm{C}$ & $1200^{\circ} \mathrm{C}$ & $800{ }^{\circ} \mathrm{C}$ & $1000^{\circ} \mathrm{C}$ & $1200^{\circ} \mathrm{C}$ \\
\hline 613 & 1,0 & 1,3 & 2,2 & 1,5 & 3,3 & 16,1 & 264,4 & 56,0 & 72,3 \\
\hline 607 & 0,9 & 1,3 & 4,1 & 1,7 & 4,9 & 12,9 & 15750,9 & 39,5 & 0,6 \\
\hline 590 & 0,8 & 1,2 & 3,9 & 2,6 & 4,7 & 11,6 & 7360,0 & 66,2 & 0,4 \\
\hline
\end{tabular}

Table 2

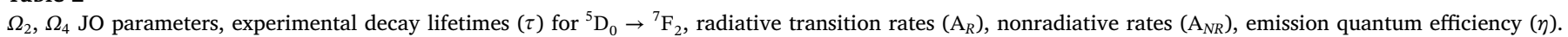

\begin{tabular}{|c|c|c|c|c|c|c|}
\hline Sample, $\mathbf{T}\left({ }^{\circ} \mathrm{C}\right)$ & $\Omega_{2}\left(\times 10^{-20} \mathrm{~cm}^{2}\right)$ & $\Omega_{4}\left(\times 10^{-20} \mathrm{~cm}^{2}\right)$ & $\tau, \mu \mathrm{s}$ & $A_{R}\left(s^{-1}\right)$ & $A_{N R}\left(s^{-1}\right)$ & $\eta, \%$ \\
\hline $5 \mathrm{Eu}, 800^{\circ} \mathrm{C}$ & 3,8 & 1,8 & 204,7 & 188 & 4697 & 3,8 \\
\hline $5 \mathrm{Eu}, 1000^{\circ} \mathrm{C}$ & 3,2 & 1,3 & 179,6 & 174 & 5395 & 3,1 \\
\hline $5 \mathrm{Eu}, 1200^{\circ} \mathrm{C}$ & 3,1 & 1,2 & 48,7 & 169 & 20,349 & 0,8 \\
\hline $10 \mathrm{Eu}, 800{ }^{\circ} \mathrm{C}$ & 4,2 & 2,0 & 117,4 & 199 & 8317 & 2,3 \\
\hline $10 \mathrm{Eu}, 1000^{\circ} \mathrm{C}$ & 3,6 & 1,1 & 57,7 & 177 & 17,166 & 1,0 \\
\hline $10 \mathrm{Eu}, 1200^{\circ} \mathrm{C}$ & 2,9 & 0,9 & 27,1 & 162 & 36,794 & 0,4 \\
\hline $5 E u 5 N b, 800^{\circ} \mathrm{C}$ & 7,5 & 2,5 & 0,1 & 261 & $7,131,676$ & 0,004 \\
\hline $5 \mathrm{Eu} 5 \mathrm{Nb}, 1000^{\circ} \mathrm{C}$ & 8,2 & 2,2 & 110,4 & 268 & 8790 & 3,0 \\
\hline $5 \mathrm{Eu} 5 \mathrm{Nb}, 1200^{\circ} \mathrm{C}$ & 5,3 & 1,9 & 914,8 & 215 & 878 & 19,7 \\
\hline
\end{tabular}

material and have been taken from Ref. [29]. Electric dipole transition strengths can be determined from the corresponding JO parameters using the following equation:

$D_{e d}=e^{2} \sum_{\lambda=2,4,6} \Omega_{\lambda}\left|\left\langle\Psi J\left\|U^{(\lambda)}\right\| \Psi^{\prime} J^{\prime}\right\rangle\right|^{2}$

The spontaneous emission probability $\mathrm{A}_{R}$ is related to electric and magnetic dipole strengths as follows:

$A\left(\Psi J, \Psi^{\prime} J^{\prime}\right)=\frac{64 \pi^{4} \nu^{3}}{3 h(2 J+1)}\left[\frac{n\left(n^{2}+2\right)^{2}}{9} D_{e d}+n^{3} D_{m d}\right]$

where $\nu$ is the average transition energy, $\mathrm{h}$ is the Planck constant $\left(6.63 \times 10^{-27}\right.$ erg s) and $2 \mathrm{~J}+1$ is the degeneracy of the initial state ${ }^{5} \mathrm{D}_{0}$. The total radiative rate $\mathrm{A}_{R}$, determined by the sum over all radiative rates can be used to calculate nonradiative rate and emission quantum efficiency $\eta$ (the ratio of photons emitted to photons absorbed by $\mathrm{Eu}^{3+}$ ions).

$A_{N R}=1 / \tau-A_{R}$

$\eta=A_{R} /\left(A_{R}+A_{N R}\right)$

For all samples $\Omega_{2}>\Omega_{4}$. This indicates that $\mathrm{Eu}^{3+}$ ions are located at asymmetric sites [33,34]. A higher $\Omega_{2}$ value indicates a more significant impact of the surrounding crystal field, which in our case means that samples annealed at lower temperatures are residing at more asymmetric sites and the ED transitions are supposedly stronger than they would be for more symmetric sites. However the increasing luminescence intensity of the $5 \mathrm{Eu} 5 \mathrm{Nb}$ sample for more symmetric sites indicates other factors (such as size of the particles) being determinative.

\section{Summary}

This study demonstrates that the $\mathrm{Nb}$ ions implemented in 4th group oxides doped with lanthanide ions drastically increase the luminescence intensity. $\mathrm{HfO}_{2}$ is the second system where this effect is demonstrated, therefore other similar systems are expected to fall in this category too. Doping with $5 \% \mathrm{Eu}$ is not sufficient for phase stabilization at higher temperatures, however samples doped with $10 \% \mathrm{Eu}$ (sufficient for phase stabilization) show lower luminescence intensity due to concentration quenching. Sample containing $\mathrm{Nb}$ has a significantly higher luminescence intensity starting at $1000{ }^{\circ} \mathrm{C}$ and higher. The partial phase change from mostly tetragonal to mostly monoclinic accompanied by an increase in luminescence intensity in the samples containing $\mathrm{Nb}$, indicates that the changes in luminescence intensity for samples not containing $\mathrm{Nb}$ are mostly due to oxygen vacancy presence and are not directly related to changes in the phase of crystallites and the resulting local crystal field. The calculated quantum efficiency also indicates a fivefold increase for the sample containing $\mathrm{Nb}$ annealed at $1200^{\circ} \mathrm{C}$.

\section{Acknowledgements}

This work was supported by the UL ISSP grant for Scientific Research Projects for Students and Young Researchers SJZ/2016/15.

\section{References}

[1] S. Lange, V. Kiisk, J. Aarik, M. Kirm, I. Sildos, Luminescence of $\mathrm{ZrO}_{2}$ and $\mathrm{HfO}_{2}$ thin films implanted with Eu and Er ions, Phys. Status Solidi (C) Curr. Top. Solid State Phys. 4 (3) (2007) 938-941, http://dx.doi.org/10.1002/pssc.200673804.

[2] N. Kumar, B.P.A. George, H. Abrahamse, V. Parashar, S.S. Ray, J.C. Ngila, A novel approach to low-temperature synthesis of cubic $\mathrm{HfO}_{2}$ nanostructures and their cytotoxicity, Sci. Rep. 7 (1) (2017) 9351, http://dx.doi.org/10.1038/s41598-01707753-0.

[3] C.H. Lu, J.M. Raitano, S. Khalid, L. Zhang, S.W. Chan, Cubic phase stabilization in nanoparticles of hafnia-zirconia oxides: particle-size and annealing environment effects, J. Appl. Phys. 103 (12) (2008), http://dx.doi.org/10.1063/1.2936983.

[4] C.L. Ordonez-Romero, C. Flores J, J. Hernandez A, E. Camarillo G., E. Cabrera B., M. Garcia-Hipolito, H. Murrieta S., Effects of the $\mathrm{HfO}_{2}$ sinterization temperature on the erbium luminescence, J. Lumin. 145 (3) (2014) 713-716, http://dx.doi.org/10. 1016/j.jlumin.2013.08.050.

[5] C. Leluyer, M. Villanueva-Ibanez, A. Pillonnet, C. Dujardin, M. Villanueva-Ibañ, $\mathrm{HfO}_{2}: \mathrm{X}\left(\mathrm{X}=\mathrm{Eu}^{3+}, \mathrm{Ce}^{3+}, \mathrm{Y}^{3+}\right)$ sol gel powders for ultradense scintillating materials, J. Phys. Chem. A 112 (41) (2008) 10152-10155, http://dx.doi.org/10.1021/ jp803339n.

[6] G.D. Wilk, R.M. Wallace, J.M. Anthony, High- $\kappa$ gate dielectrics: current status and materials properties considerations, J. Appl. Phys. 89 (10) (2001) 5243-5275, http://dx.doi.org/10.1063/1.1361065.

[7] J. Robertson, High dielectric constant gate oxides for metal oxide Si transistors, Rep. Prog. Phys. 69 (2) (2006) 327-396, http://dx.doi.org/10.1088/0034-4885 69/2/R02.

[8] T. Nadu, T. Nadu, P. Kavitha, R. Ramesh, M.R. Rajan, C. Stella, Synthesis and Characterization of Cerium Oxide Nanoparticles by Using Rapid Precipitation Method, vol. 8, 2015, pp. 91-93.

[9] S. Fabris, A.T. Paxton, M.W. Finnis, A stabilization mechanism of zirconia based on oxygen vacancies only, Acta Mater. 50 (20) (2002) 5171-5178, http://dx.doi.org/ 10.1016/S1359-6454(02)00385-3.

[10] K. Smits, D. Olsteins, A. Zolotarjovs, K. Laganovska, D. Millers, R. Ignatans, J. Grabis, Doped zirconia phase and luminescence dependence on the nature of charge compensation, Sci. Rep. 7 (2017) 44453, http://dx.doi.org/10.1038/ srep44453 (November 2016).

[11] K. Smits, A. Sarakovskis, L. Grigorjeva, D. Millers, J. Grabis, The role of Nb in intensity increase of Er ion upconversion luminescence in zirconia, J. Appl. Phys. 115 (21) (2014) 1-9, http://dx.doi.org/10.1063/1.4882262. 
[12] L. Puust, V. Kiisk, M. Eltermann, H. Mändar, R. Saar, S. Lange, I. Sildos, L. Dolgov, L. Matisen, R. Jaaniso, Effect of ambient oxygen on the photoluminescence of solgel-derived nanocrystalline $\mathrm{zro}_{2}$ :eu,nb, J. Phys. D: Appl. Phys. 50 (21) (2017) 215303.

[13] R. Ramos-González, L. García-Cerda, H.N. Alshareef, B. Gnade, M. Quevedo-López, Study of hafnium (IV) oxide nanoparticles synthesized by polymerized complex and polymer precursor derived sol-gel methods, Mater. Sci. Forum 644 (2010) 75-78, http://dx.doi.org/10.4028/www.scientific.net/MSF.644.75.

[14] J. Meng, D.Y. Jiang, Q. Li, Luminescent properties of $\mathrm{Eu}^{3+}$ doped $\mathrm{HfO}_{2}$ powders prepared by combustion, Key Eng. Mater. 434-435 (3) (2010) 805-807, http://dx. doi.org/10.4028/www.scientific.net/KEM.434-435.805.

[15] R.K. Tamrakar, D.P. Bisen, K. Upadhyay, Photoluminescence behavior of $\mathrm{ZrO}_{2} \mathrm{Eu}^{3+}$ with variable concentration of $\mathrm{Eu}^{3+}$ doped phosphor, J. Radiat. Res. Appl. Sci. 8 (1) (2015) 11-16, http://dx.doi.org/10.1016/j.jrras.2014.10.004.

[16] I. Martínez-Merlín, J. Guzmán-Mendoza, M. García-Hipólito, V.M. SánchezResendiz, L. Lartundo-Rojas, R.J. Fragoso, C. Falcony, Transparent and low surface roughness $\mathrm{HfO}_{2}: \mathrm{Tb}^{3+}, \mathrm{Eu}^{3+}$ luminescent thin films deposited by USP technique, Ceram. Int. 42 (2) (2016) 2446-2455, http://dx.doi.org/10.1016/j.ceramint.2015. 10.045 .

[17] V. Kiisk, L. Puust, H. Mandar, P. Ritslaid, M. Rahn, I. Bite, D. Jankovica, I. Sildos, R. Jaaniso, Phase stability and oxygen-sensitive photoluminescence of $\mathrm{ZrO}_{2}: \mathrm{Eu}, \mathrm{Nb}$ nanopowders, Mater. Chem. Phys. (2018), http://dx.doi.org/10.1016/j. matchemphys.2018.04.090.

[18] J.I. Langford, A.J.C. Wilson, Scherrer after sixty years: a survey and some new results in the determination of crystallite size, J. Appl. Crystallogr. 11 (2) (1978) 102-113, http://dx.doi.org/10.1107/S0021889878012844.

[19] R. Chen, Glow curves with general order kinetics, J. Electrochem. Soc. 116 (9) (1969) 1254, http://dx.doi.org/10.1149/1.2412291.

[20] J. Hu, F. Zhu, I. Matulionis, T. Deutsch, N. Gaillard, E. Miller, A. Madan, Mater. Res. Soc. Symp. Proc., vol. 1193(1), Materials Research Society, Materials Research, 2009, pp. 2-7. 〈http://dx.doi.org/10.1557/PROC-1144-LL16-04〉.

[21] A. Lauria, I. Villa, M. Fasoli, M. Niederberger, A. Vedda, Multifunctional role of rare earth doping in optical materials: nonaqueous sol-gel synthesis of stabilized cubic $\mathrm{HfO}_{2}$ luminescent nanoparticles, ACS Nano 7 (8) (2013) 7041-7052, http://dx.doi. org/10.1021/nn402357s.

[22] L.X. Liu, Z.W. Ma, Y.Z. Xie, Y.R. Su, H.T. Zhao, M. Zhou, J.Y. Zhou, J. Li, E.Q. Xie, Photoluminescence of rare earth ${ }^{3+}$ doped uniaxially aligned $\mathrm{HfO}_{2}$ nanotubes prepared by sputtering with electrospun polyvinylpyrolidone nanofibers as templates, J. Appl. Phys. 107 (2) (2010) 0-5, http://dx.doi.org/10.1063/1.3290974.

[23] K. Smits, L. Grigorjeva, D. Millers, A. Sarakovskis, A. Opalinska, J.D. Fidelus,
W. Lojkowski, Europium doped zirconia luminescence, Opt. Mater. 32 (8) (2010) 827-831, http://dx.doi.org/10.1016/j.optmat.2010.03.002.

[24] L.a. Díaz-Torres, E.D.L. Rosa-Cruz, P. Salas, C. Angeles-Chavez, Concentration enhanced red upconversion in nanocrystalline $\mathrm{ZrO}_{2}$ : Er under IR excitation, J. Phys. D Appl. Phys. 37 (18) (2004) 2489-2495, http://dx.doi.org/10.1088/0022-3727/37/ 18/004.

[25] M.R.N. Soares, T. Holz, F. Oliveira, F.M. Costa, T. Monteiro, Tunable green to red $\mathrm{ZrO}_{2}$ :Er nanophosphors, RSC Adv. 5 (26) (2015) 20138-20147, http://dx.doi.org/ 10.1039/C5RA00189G.

[26] K. Smits, D. Jankovica, A. Sarakovskis, D. Millers, Up-conversion luminescence dependence on structure in zirconia nanocrystals, Opt. Mater. 35 (3) (2013) 462-466, http://dx.doi.org/10.1016/j.optmat.2012.09.038.

[27] K. Binnemans, Interpretation of europium(III) spectra, Coord. Chem. Rev. 295 (2015) 1-45, http://dx.doi.org/10.1016/j.ccr.2015.02.015.

[28] H.Q. Liu, L.L. Wang, S.G. Chen, B.S. Zou, Optical properties of nanocrystal and bulk $\mathrm{ZrO}_{2}: \mathrm{Eu}^{3+}$, J. Alloy. Compd. 448 (1-2) (2008) 336-339, http://dx.doi.org/10. 1016/j.jallcom.2006.11.171.

[29] O. Malta, M. dos Santos, L. Thompson, N. Ito, Intensity parameters of $4 \mathrm{f}-4 \mathrm{f}$ transitions in the eu(dipivaloylmethanate)3 1,10-phenanthroline complex, J. Lumin. 69 (2) (1996) 77-84, http://dx.doi.org/10.1016/0022-2313(96)00084-1.

[30] L. Dačanin, S.R. Lukić, D.M. Petrović, M. Nikolić, M.D. Dramićanin, Judd-Ofelt analysis of luminescence emission from $\mathrm{Zn}_{2} \mathrm{SiO}_{4}: \mathrm{Eu}^{3+}$ nanoparticles obtained by a polymer-assisted solgel method, Phys. B: Condens. Matter 406 (11) (2011) 2319-2322, http://dx.doi.org/10.1016/j.physb.2011.03.068.

[31] C. Görller-Walrand, L. Fluyt, A. Ceulemans, W.T. Carnall, Magnetic dipole transitions as standards for Judd-Ofelt parametrization in lanthanide spectra, J. Chem. Phys. 95 (5) (1991) 3099-3106, http://dx.doi.org/10.1063/1.460867.

[32] F.L. Martínez, M. Toledano-Luque, J.J. Gandía, J. Cárabe, W. Bohne, J. Röhrich, E. Strub, I. Mártil, Optical properties and structure of $\mathrm{HfO}_{2}$ thin films grown by high pressure reactive sputtering, J. Phys. D: Appl. Phys. 40 (17) (2007) 5256-5265, http://dx.doi.org/10.1088/0022-3727/40/17/037.

[33] S. Tanabe, T. Ohyagi, N. Soga, T. Hanada, Compositional dependence of Judd-Ofelt parameters of $\mathrm{Er}^{3+}$ ions in alkali-metal borate glasses, Phys. Rev. B 46 (6) (1992) 3305-3310, http://dx.doi.org/10.1103/PhysRevB.46.3305.

[34] S. Prasanna Kumar, R. Hari Krishna, N. Kottam, P. Krishna Murthy, C. Manjunatha, R. Preetham, C. Shivakumara, T. Thomas, Understanding the photoluminescence behaviour in nano $\mathrm{CaZrO}_{3}: \mathrm{Eu}^{3+}$ pigments by Judd-Ofelt intensity parameters, Dyes Pigments 150 (2018) 306-314, http://dx.doi.org/10.1016/j.dyepig.2017.12.022 (December 2017). 